\title{
Vitamin D Status in Children with Chronic Kidney Disease
}

\author{
Deborah R. Stein, MD ${ }^{1}$, Henry A. Feldman, PhD, and Catherine M. Gordon, MD, MSc
}

\section{Abstract}

Background-The role of vitamin D status in patients with renal insufficiency and its relation to dietary intake and parathyroid hormone (PTH) secretion is of utmost interest given the morbidity and mortality associated with the disordered mineral metabolism seen in chronic kidney disease.

Methods-We conducted a cross-sectional study of 100 pediatric patients with a diagnosis of CKD Stage 1-5 at Children's Hospital Boston, measuring blood levels of 25OHD, 1,25(OH $)_{2} \mathrm{D}$, and parathyroid hormone and obtaining data on nutrient intake and other variables related to vitamin D status.

Results-Subjects ranged in age from 6 mo to $18 \mathrm{yr}$. 60 were male, 40 female. Sixteen percent were deficient in 25OHD ( $\_0 \mathrm{ng} / \mathrm{mL}$ ) and another $24 \%$, insufficient ( $30 \mathrm{ng} / \mathrm{mL}$ ), with $40 \%$ in the suboptimal range. Serum 25OHD and dietary vitamin D intake were not correlated.

Conclusions-We found a high prevalence of hyperparathyroidism in early-stage CKD and a significant relationship between 25OHD and PTH regardless of calcitriol level. Our study results support the suggestion that optimization of vitamin D levels may provide additional benefit in preventing or improving hyperparathyroidism in patients with early chronic kidney disease and is likely still important as an adjunctive therapy in children with advanced chronic kidney disease.

\section{Keywords}

25-hydroxyvitamin D; Parathyroid hormone; Vitamin D insufficiency; Vitamin D deficiency; Chronic kidney disease; Hyperparathyroidism

\section{Introduction}

An enhanced understanding of the role of vitamin D status in patients with renal insufficiency and its relation to dietary intake and parathyroid hormone (PTH) secretion has the potential to change supplementation practices and the clinical care of these patients.

Vitamin D is obtained from both the diet and upon exposure to ultraviolet light [1]. Precursors of vitamin D2 or D3 are hydroxylated in the liver to form 25-hydroxyvitamin D $[25(\mathrm{OH}) \mathrm{D}]$. A second hydroxylation occurs primarily in the kidney, leading to formation of 1,25-dihydroxyvitamin $\mathrm{D}\left[1,25(\mathrm{OH})_{2} \mathrm{D}\right]$ (calcitriol). Calcitriol regulates intestinal absorption of calcium, bone resorption, and renal excretion of calcium and phosphate. Significant alterations in renal func- tion, such as those found in chronic kidney disease (CKD), result in decreased activity of renal 1-alpha-hydroxylase [2], leading to decreased production of calcitriol. This in turn leads to decreased intestinal absorption of calcium and reduced renal phosphate excretion, resulting in hypocalcemia and hyperphosphatemia.

Hypocalcemia reduces the activity of the calcium-sensing receptor in the parathyroid gland and stimulates the secretion of PTH [3]. PTH, in response to both low serum calcium and

\footnotetext{
${ }^{1}$ Corresponding Author: Deborah R. Stein MD, Children's Hospital Boston Division of Nephrology, 300 Longwood Avenue, Hunnewell 319, Boston, MA 02115, Ph: 617.355.6129, Fax: 617.730.0569, Email: deborah.stein@ childrens.harvard.edu.
} 
elevated serum phosphate levels, increases the tubular reabsorption of calcium and the tubular secretion of phosphate, and stimulates the renal enzyme 1-alpha- hydroxylase to produce $1,25(\mathrm{OH})_{2} \mathrm{D}$. However, as noted above, patients with CKD are not able to produce adequate amounts of $1,25(\mathrm{OH})_{2} \mathrm{D}$. These patients may also have poor baseline nutritional intake related to uremia-induced reduction of appetite, as well as dietary restriction of specific nutrients, such as phosphorus, leading to inadequate substrate for conversion to calcitriol.

In normal subjects, the secretion of PTH is inhibited by the presence of fibroblast growth factor-23 (FGF-23), a phosphaturic hormone, and its co-receptor Klotho [4]. However, unlike PTH, FGF-23 inhibits 1-alpha hydroxylation of 25(OH)D [5] and, consequently, the production of calcitriol is limited still further in patients with CKD as the FGF-23 level rises $[6,7]$. The FGF-23 level may rise early in CKD to prevent hyperphosphatemia [8] and has been associated with a poor renal prognosis, but the underlying mechanism remains elusive, and thus the measurement of FGF-23 is of unclear clinical significance [9, 10]. Hence, several factors in CKD may contribute to disturbances in these pathways or disordered mineral metabolism. Secondary hyperparathyroidism ensues, which leads to highturnover bone disease, known as chronic kidney disease mineral and bone disorder (CKD-MBD) [11].

There are few studies to date examining the prevalence of vitamin D deficiency or insufficiency in the context of CKD [7, 12-15]. Because of the potential for a lack of $25(\mathrm{OH}) \mathrm{D}$ substrate compromising the ability to produce sufficient $1,25(\mathrm{OH})_{2} \mathrm{D}$, it may be important to evaluate both $25 \mathrm{OHD}$ and $1,25(\mathrm{OH})_{2} \mathrm{D}$ levels in the CKD population. Furthermore, measurement of 25OHD levels in patients with CKD has been of unclear value in the past, when clinical care focused on prevention and treatment of hyperparathy- roidism with calcitriol. Beyond its effects on bone, vitamin D deficiency has been associated with multiple other deleterious effects, including hypertension, cardiovascular morbidity, inflammation, and cancer risk $[6,16]$. While evaluation for these effects was beyond the scope of this study, establishing the prevalence of vitamin D deficiency and insufficiency is an important step in identifying risk factors for such conditions. Therefore, this study was undertaken to demonstrate trends in $25 \mathrm{OHD}$ and $1,25(\mathrm{OH})_{2} \mathrm{D}$ levels in patients with CKD. Additionally, the relationship of vitamin D to nutritional intake has not been studied in pediatric CKD patients who may have unique factors con- tributing to dietary exacerbation of vitamin D deficiency.

The aims of this study were to determine: (1) the prevalence of vitamin D deficiency and insufficiency in children with CKD; (2) the impact of vitamin D levels on hyperparathyroidism in pediatric patients with renal insufficiency; (3) the impact of nutritional intake on vitamin D status in this population.

\section{Methods}

This was a cross-sectional prospective study of 100 pediatric patients with a diagnosis of CKD who were attending the outpatient clinics at Children's Hospital Boston. We enrolled children aged 6 months to 18 years with CKD stages 1,2,3,4, and 5, including 5D, based on estimated glomerular filtration rate (eGFR) using the most recent bedside Schwartz calcula- tion [17]. Potential participants were approached during a routine visit to the Division of Nephrology at Children's Hospital Boston. CKD stage was classified using the Kidney Disease Outcome Quality Initiative (K/DOQI) guidelines [18]. Subjects who had received kidney transplants were categorized according to eGFR as this is carried out in clinical practice to guide monitoring and therapy of CKD. 
Children with renal transplants were only enrolled if they were a minimum of 6 months post-transplant at the time of recruitment, and those who were on dialysis had to be on a stable regimen at the time of enrollment. Approval from the Committee on Clinical Investigation, the Children's Hospital Boston Institutional Review Board, was obtained prior to initiation of the study.

Following subject assent and parental informed consent for those patients aged $<18$ years and subject consent from those who were 18 years old, clinical laboratory test results were obtained concurrently with study measurements. For all subjects, serum PTH and creatinine were obtained as part of the clinical testing, and $25(\mathrm{OH}) \mathrm{D}, 1,25(\mathrm{OH})_{2} \mathrm{D}$ and alkaline phosphatase levels were obtained as part of the research assessment. Subjects were enrolled from January 2010 to March 2011.

A demographic form was completed at enrollment that included a skin pigmentary response scale, as has been used previously [19]. A previously validated sun sensitivity scale was also included in the intake form [19]. We obtained up to three 24-h food recalls per subject using the Nutrition Data System for Research (NDS-R), a standard measurement tool for nutrient intake, which provides an average of the vitamin D dietary intake for a 24-h period (NDSR, University of Minnesota, Minneapolis, MN). Vitamins and supplements were included in this analysis, but calcium-based phosphate binders were excluded as the theoretical absorption of calcium from these products is minimal. Note was made of medications (e.g., calcitriol, phosphate binders), as well as formula type and recipe, if applicable, to complete the nutritional assessment.

Additional data were obtained from the clinic intake sheet, including height, weight, and blood pressure. Height and weight percentiles were recorded based on standardized growth charts, and body mass index was calculated. Blood pressure was categorized according to percentile for age and height based on the Fourth Task Force Guidelines [20]. The subject's medical record was reviewed and pertinent clinical information and laboratory data abstracted, such as the original renal disease, time on dialysis (when applicable), and date of transplant (when applicable).

Information about the month and season during which the subject was enrolled was obtained as this is an important variable to consider given the effects of sunlight exposure on vitamin D synthesis. At initiation of the study, April- September was defined as the period of sunny months, while October-March was defined as the period of non- sunny months in our region of the northeastern USA.

25(OH)D samples were batched, and the analysis was performed at Harvard Catalyst Central Laboratory, a CLIA- certified core analytical laboratory, using radioimmunoassay (RIA; Diasorin, Stillwater, MN). The intra-assay coefficient of variation (CV) was 4.4-8.3\%, and the inter-assay $\mathrm{CV}$ was $6.2-12.5 \% \cdot 1,25(\mathrm{OH})_{2} \mathrm{D}$ and alkaline phosphatase were an- alyzed at LabCorp by column chromatography, RIA, and kinetic methods. Both $1,25(\mathrm{OH})_{2} \mathrm{D}$ and alkaline phospha- tase were sent to LabCorp within $24 \mathrm{~h}$ of subject enrollment due to established difficulties in storing these samples for later processing. Serum chemistries were determined in the Children's Hospital Boston clinical lab, as was plasma intact PTH (iPTH), which was measured by solid- phase, two-site chemiluminescent enzyme-labeled immunometric assay (Immulite 2000; Diagnostic Products Corp, Los Angeles, CA; intra-assay CV 4.2-5.7\%, inter- assay CV 6.3-8.8\%).

25(OH)D deficiency was defined as a concentration of $\_0 \mathrm{ng} / \mathrm{mL}$, and insufficiency as $>20$ but $30 \mathrm{ng} / \mathrm{mL}$. Correlations between vitamin D levels and PTH, calcium, phosphorus, nutritional intake, and stage of CKD were assessed. Alkaline phosphatase was used as a marker of bone turnover. Serum bicarbonate was noted as a measure of acidosis. 
Levels of 25OHD were compared across clinical categories by Student's $t$ test, and the prevalence of 25(OH)D deficiency was compared across categories by the Fisher exact test. Correlation among laboratory measures was assessed by the Spearman rank correlation coefficient $\left(r_{s}\right)$ to allow for skewed distributions. Multiple linear regression techniques were used to construct a model for $25(\mathrm{OH}) \mathrm{D}$ level, depending jointly on clinical measures $\left[1,25(\mathrm{OH})_{2} \mathrm{D}, \mathrm{eGFR}, \mathrm{PTH}\right]$ and the two sun sensitivity scales. PTH level was logtransformed for entry into the regression model to compensate for its skewed distribution. The regression effect of PTH is reported as the response to a twofold increase; the other effects are reported per unit concentration or per scale unit. Multiple logistic regression was similarly employed to model the dichotomous endpoints of $25(\mathrm{OH}) \mathrm{D}$ deficiency and hyperparathyroidism. Computations were performed with SPSS Release 18.0 (SPSS, Chicago, IL) and SAS ver. 9.2 (SAS Institute, Cary, NC).

\section{Results}

Characteristics of enrolled subjects are summarized in Table 1. The predominance of boys was consistent with the higher prevalence of congenital urologic issues in boys. Race in the sample was consistent with our current clinical demographic. Of those born preterm, nine were born at $₫ 32$ weeks. Subject enrollment was balanced between the sunnier months and darker months.

\section{Vitamin D status}

Laboratory results are summarized in Table 2 . Of the 99 subjects for whom data were available, $16 \%$ had a $25(\mathrm{OH}) \mathrm{D}$ level of $\_20 \mathrm{ng} / \mathrm{mL}$, with another $24 \%$ with levels between 20 and $30 \mathrm{ng} / \mathrm{mL}$, for a total of $40 \%$ of subjects with suboptimal vitamin D levels.

The level of $25(\mathrm{OH}) \mathrm{D}$ did not vary significantly across stages of CKD, but $1,25(\mathrm{OH})_{2} \mathrm{D}$ levels were lower in the more advanced stages, while PTH and phosphorus levels were higher (Fig. 1). Alkaline phosphatase level did not vary with CKD stage.

We found no difference in mean 25(OH)D level or prev- alence of vitamin D deficiency between those with CKD stage 1, 2, 3 versus those with CKD stages 4, 5 (Table 3). The difference remained non-significant after controlling for sun sensitivity, sun exposure, and skin pigmentary response to the sun. There was no difference in mean $25(\mathrm{OH}) \mathrm{D}$ level between those enrolled during the sunny months compared to those enrolled during nonsunny months. Those taking vitamin D supplements, including vitamin D/calcium and vitamin $\mathrm{D} /$ fish oil supplements, were no more likely to be vitamin $\mathrm{D}$ deficient.

Time spent outside varied from less than 30 min per day to more than $2 \mathrm{~h}$ per day, with a mean of between 1 and $2 \mathrm{~h}$ daily ( $\$ 0$ min: $\mathrm{n} 017$; between 30 min to $1 \mathrm{~h}$ : $\mathrm{n} 026 ; 1-2 \mathrm{~h}, \mathrm{n}$ $036 ;>2 \mathrm{~h}: \mathrm{n} 021$ ). Those percentages did not vary significantly across CKD stages (Spearman $\mathrm{r} 0-0.01, \mathrm{p} 0$ 0.95). Although more time was spent outdoors in the sunny season than in the dark season (p00.002), the mean $25(\mathrm{OH}) \mathrm{D}$ level was not associated with either the season ( 00.12 ; Table 3 ) or with time spent outside ( $\mathrm{r} 0-0.05$, p 0 0.60). Sunscreen was reported to be worn by $65 \%$ of subjects at the time of enrollment, and skin exposure was also limited, with $43 \%$ reporting minimal (face/neck) exposure, $52 \%$ reporting moderate (arms/legs) exposure, and $5 \%$ reporting high exposure (bathing suit).

Among the 36 participants receiving calcitriol, five were also receiving supplemental vitamin D. Users of calcitriol were more likely to have advanced CKD, with 26/35 (72\%) in stages 4-5 as compared to $4 / 59$ non-users $(7 \%, \mathrm{p}<0.0001)$, but the use of calcitriol was not associated with $25(\mathrm{OH}) \mathrm{D}$ level or deficiency (Table 3). Suboptimal vitamin D status was 
associated with steroid use (see Fig. 2). Nine subjects had a history of fracture, but there was no correlation between vitamin D status and fractures.

There was a mild, but significant correlation between $25(\mathrm{OH}) \mathrm{D}$ and $1,25(\mathrm{OH})_{2} \mathrm{D}$ levels $\left(\mathrm{r}_{\mathrm{S}}\right.$ $00.38, \mathrm{p}<0.001)$, and an inverse correlation between 25(OH)D and PTH $\left(\mathrm{r}_{\mathrm{s}} 0-0.20, \mathrm{p}<\right.$ $0.05)$, as well as a significant relationship between PTH and alkaline phosphatase $\left(\mathrm{r}_{\mathrm{s}} 00.20\right.$, $\mathrm{p}<0.05)$. Calcitriol levels were lower in subjects with a lower eGFR $\left(\mathrm{r}_{\mathrm{s}} 00.379, \mathrm{p}<0.001\right)$. PTH was associated with lower levels of calcium $\left(\mathrm{r}_{\mathrm{s}} 0-0.29\right.$, p 00.004$)$ and eGFR $\left(\mathrm{r}_{\mathrm{s}} 0-\right.$ $0.458, \mathrm{p}<0.001)$ and increasing levels of phosphorus $\left(\mathrm{r}_{\mathrm{s}} 00.32, \mathrm{p} 00.001\right)$.

The results of multivariate modeling of 25(OH)D deficiency and insufficiency are shown in Table 4. A higher likelihood of deficiency or insufficiency of $25(\mathrm{OH}) \mathrm{D}$ was seen in those with higher PTH levels. A lower likelihood of deficiency or insufficiency was seen in those with higher $1,25(\mathrm{OH})_{2} \mathrm{D}$ levels, those most sensitive to the sun, and those who tan the most in response to the sun. $25(\mathrm{OH}) \mathrm{D}$ insufficiency was also more likely in those with higher eGFR. The addition of vitamin D intake and time spent outside did not alter the results of these models.

\section{Hyperparathyroidism}

As shown in Table 4, those with higher 25(OH)D levels were less likely to have hyperparathyroidism. This finding held true even after controlling for $1,25(\mathrm{OH})_{2} \mathrm{D}$ levels and eGFR. Those with higher $1,25(\mathrm{OH})_{2} \mathrm{D}$ levels were also more likely to have hyperparathyroidism, and in this model, those with higher eGFR were less likely to have hyperparathyroidism.

Mean PTH increased with increasing stage of CKD. We found a total of 48 subjects with a PTH higher than the recommended target, as per KDOQI guidelines. The inci- dence of hyperparathyroidism varied between the different stages of CKD and was lowest in those with CKD 1, but parathyroidism was present even in early CKD (Fig. 3). Among the 35 subjects receiving calcitriol, 17 had a PTH concentration within the target range. Those with CKD stages 4 and 5 were not more likely to have hyperparathy- roidism, as defined by the KDOQI guidelines, than those with CKD stages 1, 2, 3 (Fisher exact test p00.825).

\section{Nutritional intake}

Ninety-six subjects submitted nutritional information ( 80 completed three recalls, 5 completed 2 recalls, 14 completed 1 recall). Due to time constraints or difficulty in being reached, not all subjects provided a dietary history. Vitamin D intake was assessed, but was highly variable, with a mean intake of 568 International Units (IU) (range 18-8160 IU). This included vitamin D supplements, which ranged from 200 to 4,000 IU daily. Subjects consumed an average of three 8-ounce vitamin D-containing dairy products per day, including milk, cheese, and yogurt. Vitamin D intake did not correlate with 25(OH)D levels (Spearman's rho 0.198, p00.055.)

\section{Discussion}

In our patient sample, the prevalence of a suboptimal vitamin D status in children with CKD was comparable to that reported among healthy children and adolescents [21]. These data are in contrast to those reported in other studies which have demonstrated an increased prevalence of suboptimal vitamin D status in children with CKD as compared to healthy children. Menon et al. studied vitamin D deficiency and hyperparathyroidism in children with CKD, assessing $25(\mathrm{OH})$ D levels and $1,25(\mathrm{OH})_{2} \mathrm{D}$ levels along with PTH in a retrospective analysis to determine the effect of treatment with ergocalciferol [13]. These authors found that $77 \%$ of patients had vitamin D deficiency or insufficiency [25(OH)D 
level $<30 \mathrm{ng} / \mathrm{mL}]$ and assessed the response to treatment with ergocalciferol. Other studies have examined the prevalence of vitamin D deficiency in children with CKD, but not in relation to nutritional intake or $1,25(\mathrm{OH})_{2} \mathrm{D}$ levels. Interestingly, our study cohort had a lower prevalence of vitamin D deficiency and insufficiency than has been reported in several other studies $[13,14]$. Noteworthy is that although our study population is representative of our clinic population, our sam- ple has a lower number of black patients than the majority of other studies, and given that black patients have lower than average vitamin D levels, this may have led to the significant difference observed.

Seeherunvong et al. evaluated patients with CKD stage 1-5 and found a high prevalence of vitamin $\mathrm{D}$ deficiency and insufficiency and reported that those with more advanced CKD were more likely to have $25(\mathrm{OH}) \mathrm{D}$ levels of $<20 \mathrm{ng} / \mathrm{mL}$ than those with $\mathrm{CKD}$ at an earlier stage [14]. In contrast, we found that $25(\mathrm{OH}) \mathrm{D}$ insufficiency was more likely in those with higher eGFR. This may be due to the underrecognition of suboptimal vitamin D status in children with more preserved renal function, and in a larger sample population one would ideally exclude those already on supplementation. In our study, eGFR did not differ between those taking vitamin $\mathrm{D}$ supplements $(\mathrm{n}=11)$ and the others ( $\mathrm{p}=.57$ by $\mathrm{t}$ test), but it is possible that a larger sample would have detected a difference. It is also possible that given the geographic location of the study, time spent outside did not differ between those with varying eGFR, and thus this is less of a factor in our study in terms of vitamin D status. We did not evaluate urinary protein losses which may result in low $25(\mathrm{OH}) \mathrm{D}$ levels due to the loss of vitamin D binding protein [22], and thus unrecognized urinary losses may have led to a deficiency even in those with preserved eGFR.

In contrast to studies of healthy children [21], in which vitamin D deficiency was more prevalent during the winter months, there was no difference in $25(\mathrm{OH}) \mathrm{D}$ levels between those enrolled during the sunny months and those enrolled during non-sunny months. This finding may be related to factors associated with the chronic illness, such as ill children being less active and spending more time indoors. A longitudinal design may be able to detect changes in $25(\mathrm{OH}) \mathrm{D}$ levels among indi- vidual patients depending on season, a question that awaits further study.

Those participants who reported they took any sort of vitamin supplement had higher vitamin D levels than those who did not take any vitamins. However, this group and those specifically on vitamin D supplements were no more likely to be vitamin D replete. This finding may be explained by the fact that those with lower $25(\mathrm{OH}) \mathrm{D}$ levels had not yet been repleted after being identified as having the deficiency, or they may have been noncompliant with the prescribed treatment regimen.

We demonstrated a significant difference in mean $25(\mathrm{OH}) \mathrm{D}$ level between subjects receiving glucocorticoids and those not on this therapy, which has been reported in several other studies. Glucocorticoids are known to impair vitamin D metabolism and normal bone accretion $[1,23]$. Given that many patients with CKD receive glucocorticoids either for the underlying condition, such as vasculitis, or for immunosuppression following transplantation, this result underscores the importance of monitoring and recognizing suboptimal vitamin D status in these children.

We found a high prevalence of hyperparathyroidism early in CKD and demonstrated a significant relationship between $25(\mathrm{OH}) \mathrm{D}$ and PTH regardless of calcitriol level, consistent with the findings of Shroff et al. in a study of pediatric renal transplant recipients [24] and with those of Brodersen et al. [12]. This finding underscores the fact that the disordered mineral metabolism starts early in CKD and may contribute to the difficulty in controlling the disorder in later stages of the disease. These data are especially important given the fact 
that osteoclasts bear a PTH receptor; consequently, increased PTH concentrations accelerate the rate of bone resorption, potentially leading to long-standing ill effects on the skeleton during a critical window for peak bone accrual. Levin et al. demonstrated that low $1,25(\mathrm{OH})_{2} \mathrm{D}$ and high PTH levels were present at higher rates than previously appreciated in patients with an eGFR of $>80 \mathrm{~mL} / \mathrm{min}$ [25]. This presents an opportunity for future study as well as early intervention, as hyperparathyroidism in early CKD may lead to increasing complications during later stage CKD and transplant. In a study of 890 children on peritoneal dialysis, the majority were found to have PTH levels outside of the recommended targets, a finding of some concern [26].

Tuchman et al. noted that at 12 months post-renal transplant, iPTH was inversely associated with 25(OH)D levels, further supporting the potential role for vitamin D optimiza- tion in early CKD, or those with mild renal impairment, in helping to prevent or control worsening hyperparathyroidism [27]. Our study included an assessment of vitamin D intake, sun exposure, and both skin pigmentation and sun sensitivity and, therefore, allows for the control of other risk factors and underscores the strong influence of $25(\mathrm{OH}) \mathrm{D}$ on PTH. Calcitriol levels were lower in subjects with lower eGFR. However, there was a substantial variation in calcitriol levels for a given eGFR, highlighting the difficulty in studying these relation- ships, as those with the highest PTH are most likely to be receiving therapy with exogenous calcitriol.

Given the potential complications of calcitriol therapy for hyperparathyroidism, including hypercalcemia and resultant coronary artery calcification, supplemental vitamin D may provide another therapeutic avenue for PTH suppression in all stages of CKD. A smaller study of 42 children demon- strated a decrease in median PTH that was concurrent with an increase in $25(\mathrm{OH}) \mathrm{D}$ when large doses $(600,000 \mathrm{IU}$ over 3 days) were given to children with CKD. Belostotsky et al. demonstrated a prevalence of $58 \%$ of children with $25(\mathrm{OH}) \mathrm{D}$ levels of $<20 \mathrm{ng} / \mathrm{mL}$ and showed that high PTH levels were more common in those with $25(\mathrm{OH}) \mathrm{D}<20 \mathrm{ng} / \mathrm{mL}$ than in those with higher 25(OH)D levels [15].

The recent statement from the Institute of Medicine rec- ommends $20 \mathrm{ng} / \mathrm{mL}$ as the appropriate threshold to define vitamin D deficiency and changed the Recommended Daily Allowance (RDA) to $600 \mathrm{IU}$ daily for children and adoles- cents, aged 1-18 years. However, the authors of those recommendations acknowledge that further study is needed regarding the benefits of higher 25(OH)D levels [28]. Fur- thermore, these recommendations were targeting a healthy population and, therefore, may not be applicable to those with chronic disease, such as children and adolescents with CKD. In our study, average vitamin D intake showed no significant trend with regard to those with a dietary restric- tion, PTH, or stage of $\mathrm{CKD}$, and reported dietary intake was not associated with $25(\mathrm{OH}) \mathrm{D}$ levels. These collective find- ings underscore the need for the measurement of $25(\mathrm{OH}) \mathrm{D}$ levels rather than relying on intake information to ensure adequate levels. Previous reviews have noted that dietary intake is typically insufficient to optimize vitamin D levels, with most foods containing very small amounts of vitamin D per serving [29]. Of note, this study involved a disease group and, therefore, there may be issues associated with erratic intake, varied absorption, and urinary losses of vitamin D binding protein, which were not measured and may have affected the 25(OH)D concentration.

The KDOQI Clinical Practice Guidelines for Bone Metabolism and Disease in Children with Chronic Kidney Disease address the incomplete understanding of vitamin D and other modifiers of bone disease in the pediatric CKD population. KDOQI Guideline 8, Prevention and Treatment of Vitamin D Insufficiency and Vitamin D Deficiency, calls for “...studies to evaluate measures to minimize early secondary hyperparathy- roidism....in patients with 
CKD of all ages" [30]. Our research suggests that further studies with vitamin D supplementation may offer potential avenues for intervention in this arena.

In controlling for several variables, including sun expo- sure, exercise, supplemental intake and medications, and the relationship of these factors to 25(OH)D levels in children with $\mathrm{CKD}$, we have clarified risk factors for vitamin $\mathrm{D}$ insufficiency and deficiency unique to children with CKD. Therefore, these data may impact preventive measures iden- tified for children and adolescents. Although clinically it would appear that decreased sun exposure and dietary limitations should influence vitamin D status, we observed that these variables had no appreciable impact and that the most effective intervention is likely oral supplementation.

\section{Limitations}

This was a cross-sectional study and as such, the ability to establish causality between certain factors was limited. The sample size was small relative to many studies of adults, highlighting the difficulty in drawing broad conclusions for children with relatively rare conditions. We demonstrated a significant relationship between 25(OH)D and PTH levels regardless of calcitriol level, but longitudinal studies are needed to demonstrate causality between PTH and 25(OH) D. However, we did find a significant association between $25(\mathrm{OH}) \mathrm{D}$ and $1,25(\mathrm{OH})_{2} \mathrm{D}$ levels and a negative correlation between $25(\mathrm{OH}) \mathrm{D}$ and PTH levels, which suggests a benefit to optimizing vitamin $\mathrm{D}$ stores in patients with hyperparathyroidism.

Using serum creatinine to estimate renal function is not ideal for research purposes. However, more reliable serum markers have yet to be validated and made commercially available. The stage of CKD of subjects in this study was classified using serum creatinine to estimate renal function, which may have led to an inaccurate classification of CKD. Because we included patients who are already receiving vitamin D supplementation, our results may be less relevant to a supplement-naïve population. Additionally, we did not control for measures such as losses of vitamin $\mathrm{D}$ due to urinary losses of vitamin $\mathrm{D}$ binding protein and other hormonal influences, such as FGF-23. Vitamin D intake was highly variable, and intake was self-reported, with no method by which to confirm compliance with medications. Birth weight and prematurity documentation were based on parental history when not available in the medical record, and subjects may have altered their diets in preparation for reporting or have reported inaccurately. While medications were obtained from medical records, it was impossible to confirm compliance in many cases.

Finally, although the ethnic distribution was consistent with our clinical practice population, our sample had significantly fewer black patients than many other studies, which may limit the generalizability of these results to children in other locations.

\section{Conclusion}

In conclusion, our research serves to increase the understanding of the role of $25(\mathrm{OH}) \mathrm{D}$ in children with CKD, as well as the relationship between CKD and PTH secretion. By evaluating $25(\mathrm{OH}) \mathrm{D}$ and $1,25(\mathrm{OH})_{2} \mathrm{D}$ levels, we have shown a correlation between vitamin $\mathrm{D}$ and PTH levels, and a significant relationship between 25-hydroxyvitamin D levels and PTH in pediatric patients with severe renal disease.

\section{Acknowledgments}

The authors acknowledge the support of the Division of Nephrology, Department of Pediatrics at Children's Hospital Boston, and the Harvard Clinical and Translational Science Center (RR 025758). The authors thank Tracy 
Antonelli and Susan McDermott for assistance with study design, and Asher Schachter for his helpful input. We also thank our patients and their families who made this work possible.

\section{References}

1. Holick MF. Vitamin D deficiency. N Engl J Med. 2007; 357:266-281. [PubMed: 17634462]

2. Wesseling K, Bakkaloglu S, Salusky I. Chronic kidney disease mineral and bone disorder in children. Pediatr Nephrol. 2008; 23:195-207. [PubMed: 18046581]

3. Riccardi D, Brown EM. Physiology and pathophysiology of the calcium-sensing receptor in the kidney. Am J Physiol Renal Physiol. 2010; 298:F485-F499. [PubMed: 19923405]

4. Haussler MR, Whitfield GK, Kaneko I, Forster R, Saini R, Hsieh JC, Haussler CA, Jurutka PW. The role of vitamin D in the FGF23, klotho, and phosphate bone-kidney endocrine axis. Rev Endocr Metab Disord . 201110.1007/s11154-011-9199-8

5. Peacock M. Calcium metabolism in health and disease. Clin J Am Soc Nephrol. 2010; 5(Suppl 1):S23-S30. [PubMed: 20089499]

6. Shroff R, Wan M, Rees L. Can vitamin D slow down the progression of chronic kidney disease? Pediatr Nephrol. 201110.1007/s00467-011-2045-0

7. Kalantar-Zadeh K, Shah A, Duong U, Hechter RC, Dukkipati R, Kovesdy CP. Kidney bone disease and mortality in CKD: revisiting the role of vitamin D, calcimimetics, alkaline phosphatase, and minerals. Kidney Int. 2010; (Suppl):S10-21.

8. Wesseling-Perry K. FGF-23 in bone biology. Pediatr Nephrol. 2010; 25:603-608. [PubMed: 20012997]

9. Stubbs JR, Egwuonwu S. Is fibroblast growth factor 23 a harbinger of mortality in CKD? Pediatr Nephrol. 2011 doi:10.1007/ s00467-011-1810-4.

10. Gupta A, Winer K, Econs MJ, Marx SJ, Collins MT. FGF-23 is elevated by chronic hyperphosphatemia. J Clin Endocrinol Metab. 2004; 89:4489-4492. [PubMed: 15356053]

11. Kidney Disease: Improving Global Outcomes (KDIGO) CKD- MBD Work Group. KDIGO clinical practice guideline for the diagnosis, evaluation, prevention, and treatment of Chronic Kidney Disease-Mineral and Bone Disorder (CKD-MBD). Kidney Int. 2009; (Suppl):S1-130.

12. Brodersen LA, Nielsen PR, Thiesson HC, Marckmann P. Vitamin D status in children and adolescents with kidney trans- plants. Pediatr Transplant. 2011; 15:384-389. [PubMed: 21366811]

13. Menon S, Valentini RP, Hidalgo G, Peschansky L, Mattoo TK. Vitamin D insufficiency and hyperparathyroidism in chil- dren with chronic kidney disease. Pediatr Nephrol. 2008; 23:18311836. [PubMed: 18575896]

14. Seeherunvong W, Abitbol CL, Chandar J, Zilleruelo G, Freundlich M. Vitamin D insufficiency and deficiency in children with early chronic kidney disease. J Pediatr. 2009; 154:906-911. [PubMed: 19230902]

15. Belostotsky V, Mughal MZ, Berry JL, Webb NJ. Vitamin D deficiency in children with renal disease. Arch Dis Child. 2008; 93:959-962. [PubMed: 18463127]

16. Baeke F, Gysemans C, Korf H, Mathieu C. Vitamin D insufficiency: implications for the immune system. Pediatr Nephrol. 2010; 25:1597-160. [PubMed: 20180136]

17. Schwartz GJ, Munoz A, Schneider MF, Mak RH, Kaskel F, Warady BA, Furth SL. New equations to estimate GFR in children with CKD. J Am Soc Nephrol. 2009; 20:629-637. [PubMed: 19158356]

18. National Kidney Foundation. K/DOQI clinical practice guidelines for chronic kidney disease: evaluation, classification, and stratification. Am J Kidney Dis. 2002; 39:S1-S266. [PubMed: 11904577]

19. Gordon CM, Feldman HA, Sinclair L, Williams AL, Kleinman PK, Perez-Rossello J, Cox JE. Prevalence of vitamin D deficiency among healthy infants and toddlers. Arch Pediatr Adolesc Med. 2008; 162:505-512. [PubMed: 18524739]

20. National High Blood Pressure Education Program Working Group on High Blood Pressure in Children and Adolescents. The fourth report on the diagnosis, evaluation, and treatment of high blood pressure in children and adolescents. Pediatrics. 2004; 114:555-576. [PubMed: 15286277] 
21. Gordon CM, DePeter KC, Feldman HA, Grace E, Emans SJ. Prevalence of vitamin D deficiency among healthy adoles- cents. Arch Pediatr Adolesc Med. 2004; 158:531-537. [PubMed: 15184215]

22. Prytula A, Wells D, McLean T, Balona F, Gullett A, Knott C, Cantwell M, Hassen K, Ledermann S, Rees L, Shroff R. Urinary and dialysate losses of vitamin D-binding protein in chil- dren on chronic peritoneal dialysis. Pediatr Nephrol. 2011 doi:10.1007/ s00467-011-2045-0.

23. Dore RK. How to prevent glucocorticoid-induced osteopo- rosis. Cleve Clin J Med. 2010; 77:529_ 536. [PubMed: 20682515]

24. Shroff R, Knott C, Gullett A, Wells D, Marks SD, Rees L. Vitamin D deficiency is associated with short stature and may influence blood pressure control in paediatric renal transplant recipients. Pediatr Nephrol. 2011; 26:2227-2233. [PubMed: 21643944]

25. Levin A, Bakris GL, Molitch M, Smulders M, Tian J, Williams LA, Andress DL. Prevalence of abnormal serum vitamin D, PTH, calcium, and phosphorus in patients with chronic kidney disease: results of the study to evaluate early kidney disease. Kidney Int. 2007; 71:31-38. [PubMed: 17091124]

26. Borzych D, Rees L, Ha IS, Chua A, Valles PG, Lipka M, Zambrano P, Ahlenstiel T, Bakkaloglu SA, Spizzirri AP, Lopez L, Ozaltin F, Printza N, Hari P, Klaus G, Bak M, Vogel A, Ariceta G, Yap HK, Warady BA, Schaefer F. The bone and mineral disorder of children under- going chronic peritoneal dialysis. Kidney Int. 2010; 78:1295-1304. [PubMed: 20811335]

27. Tuchman S, Kalkwarf HJ, Zemel BS, Shults J, Wetzsteon RJ, Foerster D, Strife CF, Leonard MB. Vitamin D deficiency and parathyroid hormone levels following renal transplantation in children. Pediatr Nephrol. 2010; 25:2509-2516. [PubMed: 20872272]

28. Ross AC, Manson JE, Abrams SA, Aloia JF, Brannon PM, Clinton SK, Durazo-Arvizu RA, Gallagher JC, Gallo RL, Jones G, Kovacs CS, Mayne ST, Rosen CJ, Shapses SA. The 2011 report on dietary reference intakes for calcium and vitamin D from the Institute of Medicine: what clinicians need to know. J Clin Endo- crinol Metab. 2011; 96:53-58.

29. Shroff R, Knott C, Rees L. The virtues of vitamin D-but how much is too much? Pediatr Nephrol. 2010; 25:1607-1620. [PubMed: 20393752]

30. National Kidney Foundation. K/DOQI clinical practice guidelines for bone metabolism and disease in children with chronic kidney disease. Am J Kidney Dis. 2005; 46:S1-121. 

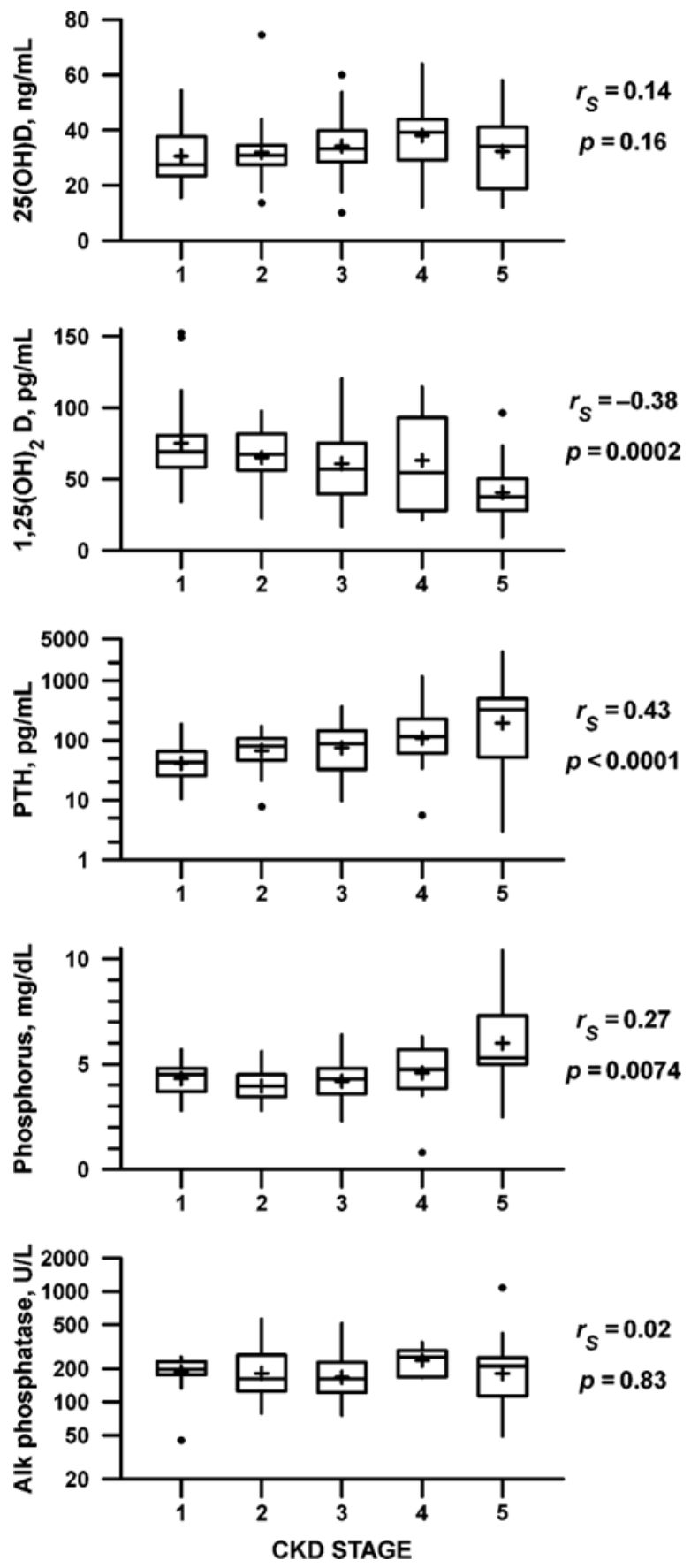

Figure 1.

Box plots illustrate distribution of serum 25(OH)D (upper panel) and related laboratories (lower panels) at 5 stages of CKD in children. 25(OH)D and alkaline phosphatase did not vary significantly across stages of $\mathrm{CKD}$, but $1,25(\mathrm{OH})_{2} \mathrm{D}$ declined while PTH and phosphorus increased. $r_{S}$ : Spearman correlation coefficient. $p$ tests $r_{S}=0$. At each stage of $\mathrm{CKD},(+)$ indicates mean. Center belt of the box indicates median; top and bottom indicate quartile boundaries (25th and 75 th percentiles). Individual points $(\bullet)$ indicate outliers, falling outside the box by at least 1.5 times its height. Vertical lines extend to position of farthest nonoutlier above and below the box. 

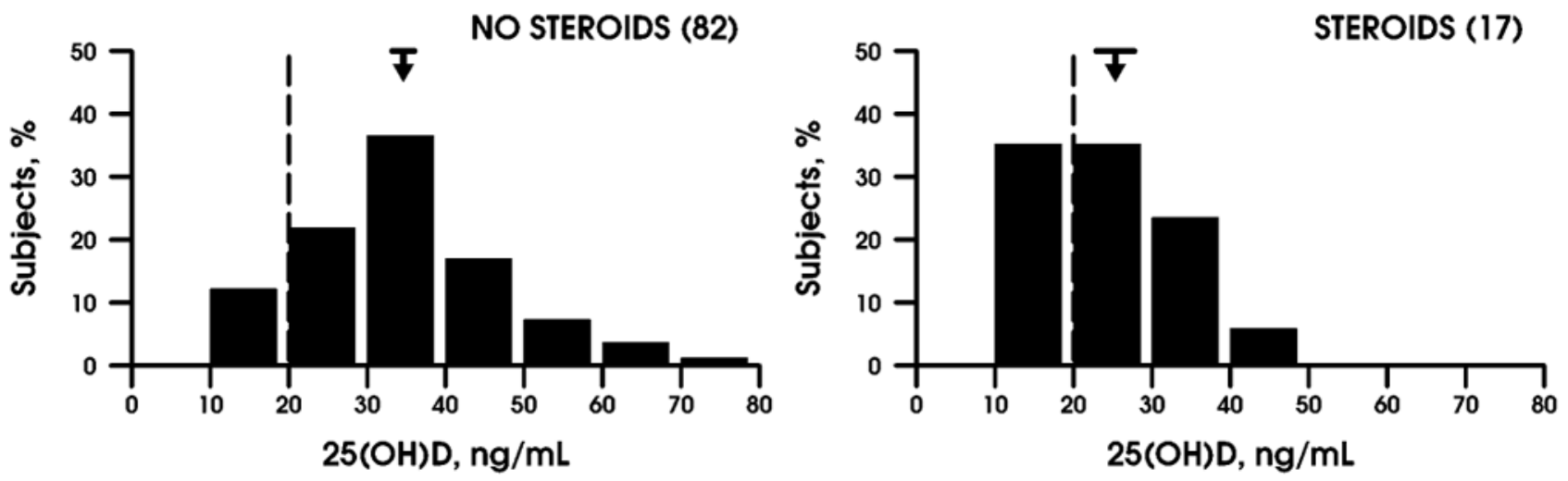

Figure 2.

Distribution of serum 25(OH)D in subjects with no history of steroid medication (left) and those with such history (right). Arrow indicates mean; crossbar indicates \pm 1 standard error. Dashed line indicates threshold for 25(OH)D deficiency $(20 \mathrm{ng} / \mathrm{mL})$. The steroid users had lower mean level ( 25.3 vs $34.6 \mathrm{ng} / \mathrm{mL}, \mathrm{p}=0.005$ ) and were more likely to be deficient ( $35 \%$ vs $12 \%, \mathrm{p}=0.03)$. 


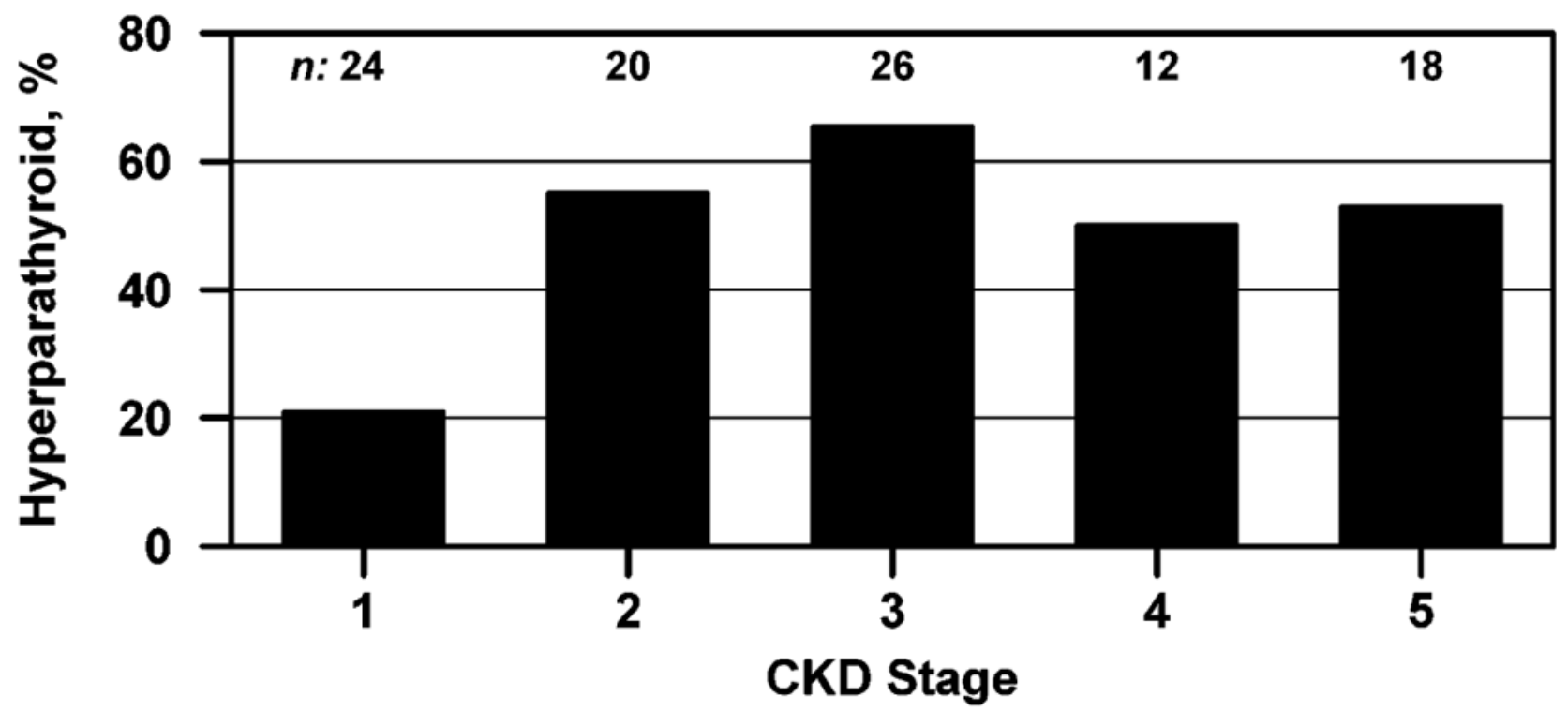

Figure 3.

Proportion of subjects with PTH greater than recommended target, by stage of CKD. n= number of subjects in each stage. Bar represents percentage with hyperparathyroidism. 
Table 1

Characteristics of 100 subjects

\begin{tabular}{|c|c|c|}
\hline & & $\mathbf{n}^{*}$ \\
\hline \multirow[t]{2}{*}{ Gender } & Boys & 60 \\
\hline & Girls & 40 \\
\hline \multirow[t]{3}{*}{ Ethnicity } & Hispanic & 14 \\
\hline & Not Hispanic & 83 \\
\hline & Don’t Know & 3 \\
\hline \multirow[t]{5}{*}{ Race $^{*}$} & White & 81 \\
\hline & Black/African American & 13 \\
\hline & Asian & 1 \\
\hline & Hawaiian/Pacific Islander & 1 \\
\hline & Other $^{a}$ & 10 \\
\hline \multirow[t]{3}{*}{ Gestation $<37$ weeks } & Yes & 27 \\
\hline & No & 72 \\
\hline & Unknown & 1 \\
\hline \multirow[t]{3}{*}{ Weight $<2.5 \mathrm{~kg}$} & Yes & 19 \\
\hline & No & 76 \\
\hline & Unknown & 5 \\
\hline \multirow[t]{2}{*}{ Enrollment period } & Sunny months (April-September) & 55 \\
\hline & Dark months (October-March) & 45 \\
\hline \multirow[t]{10}{*}{ Underlying condition ${ }^{*}$} & Obstructive uropathy & 26 \\
\hline & Dysplasia & 23 \\
\hline & Reflux nephropathy & 20 \\
\hline & Focal and segmental glomerulosclerosis & 11 \\
\hline & Cystic kidney disease & 5 \\
\hline & Hemolytic uremic syndrome & 4 \\
\hline & Shock & 4 \\
\hline & Brachio-oto-renal syndrome & 3 \\
\hline & Calcineurin inhibitor toxicity post-transplant & 3 \\
\hline & Other $b$ & 13 \\
\hline \multirow[t]{3}{*}{ Treatment as of enrollment } & Dialysis & 10 \\
\hline & Renal transplant & 33 \\
\hline & Neither & 57 \\
\hline \multirow[t]{3}{*}{ CKD Stage } & 1 & 24 \\
\hline & 2 & 20 \\
\hline & 3 & 26 \\
\hline
\end{tabular}

Pediatr Nephrol. Author manuscript; available in PMC 2013 August 21. 


\begin{tabular}{lll}
\hline & & $\mathbf{n}^{*}$ \\
\hline & 5 & 12 \\
\hline Systolic blood pressure & $<90^{\text {th }}$ percentile & 18 \\
& $90-95^{\text {th }}$ percentile & 71 \\
& $>95^{\text {th }}$ percentile & 11 \\
& Not recorded & 16 \\
\hline \multirow{2}{*}{ Diastolic blood pressure } & $<90^{\text {th }}$ percentile & 2 \\
& $90-95^{\text {th }}$ percentile & 67 \\
& $>95^{\text {th }}$ percentile & 13 \\
& Not recorded & 15 \\
\hline \multirow{2}{*}{ Vitamin supplementation } & Multivitamin & 5 \\
\cline { 2 - 3 } & Vitamin D/Fish Oil or Ca/Vit D & 35 \\
& Calcitriol & 11 \\
& Zemplar & 36 \\
& None of the above & 1 \\
\hline
\end{tabular}

Categories are not mutually exclusive; sum exceeds $100 \%$.

${ }^{a}$ Subject provided geographical response: Puerto Rican (5); South Asian (2); Latin American (1); Cape Verdean (1); Portuguese (1).

${ }^{b}$ Glomerular disease (2); Eagle-Barrett syndrome (2); Wolf-Hirschhorn syndrome (2); bilateral Wilms' tumor (1); congenital nephrotic syndrome (1); Henoch-Schonlein purpura (1); Pierson syndrome (1); primary hyperoxaluria type I (1); Wegener's granulomatosis (1); lupus nephritis (1). 
Table 2

Laboratory results ${ }^{a}$

\begin{tabular}{|c|c|c|c|c|}
\hline & $n^{*}$ & Median & Minimum & Maximum \\
\hline Bicarbonate (meq/L) & 99 & 23.0 & 15.0 & 36.0 \\
\hline$(\mathrm{mmol} / \mathrm{L})$ & & 23.0 & 15.0 & 36.0 \\
\hline Blood urea nitrogen $(\mathrm{mg} / \mathrm{dL})$ & 99 & 25.0 & 8.0 & 121.0 \\
\hline$(\mathrm{mmol} / \mathrm{L})$ & & 8.9 & 2.9 & 43.2 \\
\hline Creatinine (mg/dL) & 99 & 1.1 & 0.1 & 14.8 \\
\hline (umol/L) & & 97.2 & 8.8 & 1308.3 \\
\hline Calcium (mg/dL) & 98 & 9.8 & 8.5 & 11.4 \\
\hline$(\mathrm{mmol} / \mathrm{L})$ & & 2.5 & 2.1 & 2.9 \\
\hline Phosphorus (mg/dL) ${ }^{b}$ & 98 & 4.4 & 0.8 & 10.4 \\
\hline$(\mathrm{mmol} / \mathrm{L})$ & & 1.4 & 0.3 & 3.4 \\
\hline $\mathrm{PTH}(\mathrm{pg} / \mathrm{mL})^{\mathcal{c}}$ & 99 & 78.9 & 3.0 & 3021.0 \\
\hline$(n g / L)$ & & 78.9 & 3.0 & 3021.0 \\
\hline $25(\mathrm{OH}) \mathrm{D}(\mathrm{ng} / \mathrm{mL})$ & 99 & 32.2 & 10.1 & 74.5 \\
\hline$(\mathrm{nmol} / \mathrm{L})$ & & 80.4 & 25.2 & 186.0 \\
\hline $1,25(\mathrm{OH})_{2} \mathrm{D}(\mathrm{pg} / \mathrm{mL})^{d}$ & 96 & 61.3 & 9.1 & 152.4 \\
\hline$(\mathrm{pmol} / \mathrm{L})$ & & 159.4 & 23.7 & 396.2 \\
\hline Alkaline phosphatase (unit/L) & 98 & 192.5 & 45.0 & 1081.0 \\
\hline$($ ukat/L) & & 3.2 & 0.8 & 18.1 \\
\hline $\begin{array}{l}\text { Laboratory data were unavailab } \\
\text { SI Units are represented in italic }\end{array}$ & SI Units are represented in italics on the second line for each laboratory value & small num & ne for each la 100 & $\begin{array}{l}\text { subjects due } \\
\text { poratory valu }\end{array}$ \\
\hline \multicolumn{5}{|c|}{$b_{\text {Normal range }} 3-5.7 \mathrm{mg} / \mathrm{dL}$} \\
\hline Normal range $10-65 \mathrm{pg} / \mathrm{mL}$ & & & & \\
\hline Normal range $10-75 \mathrm{pg} / \mathrm{mL}$ & & & & \\
\hline
\end{tabular}

Pediatr Nephrol. Author manuscript; available in PMC 2013 August 21. 


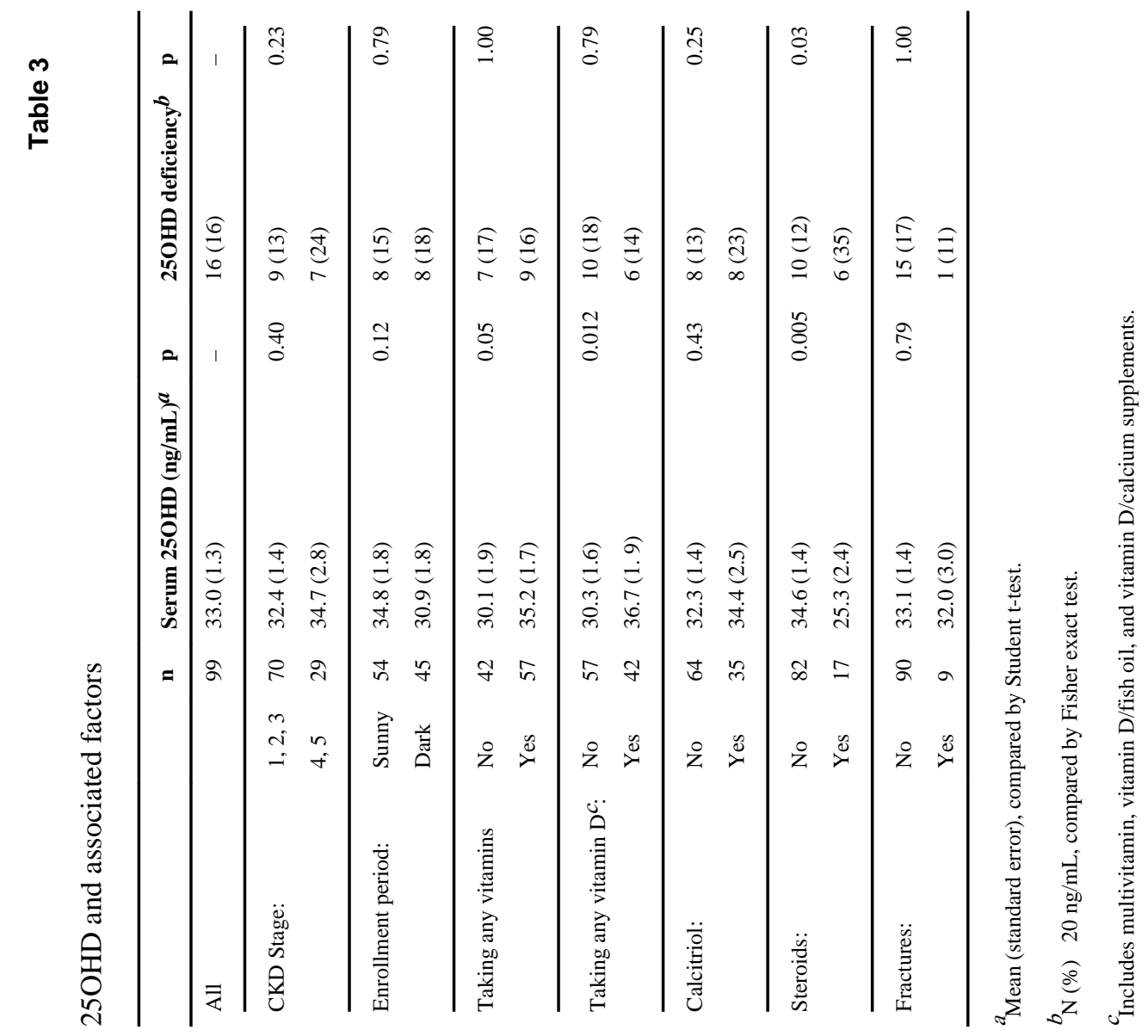




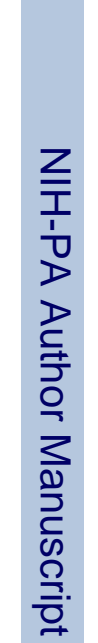

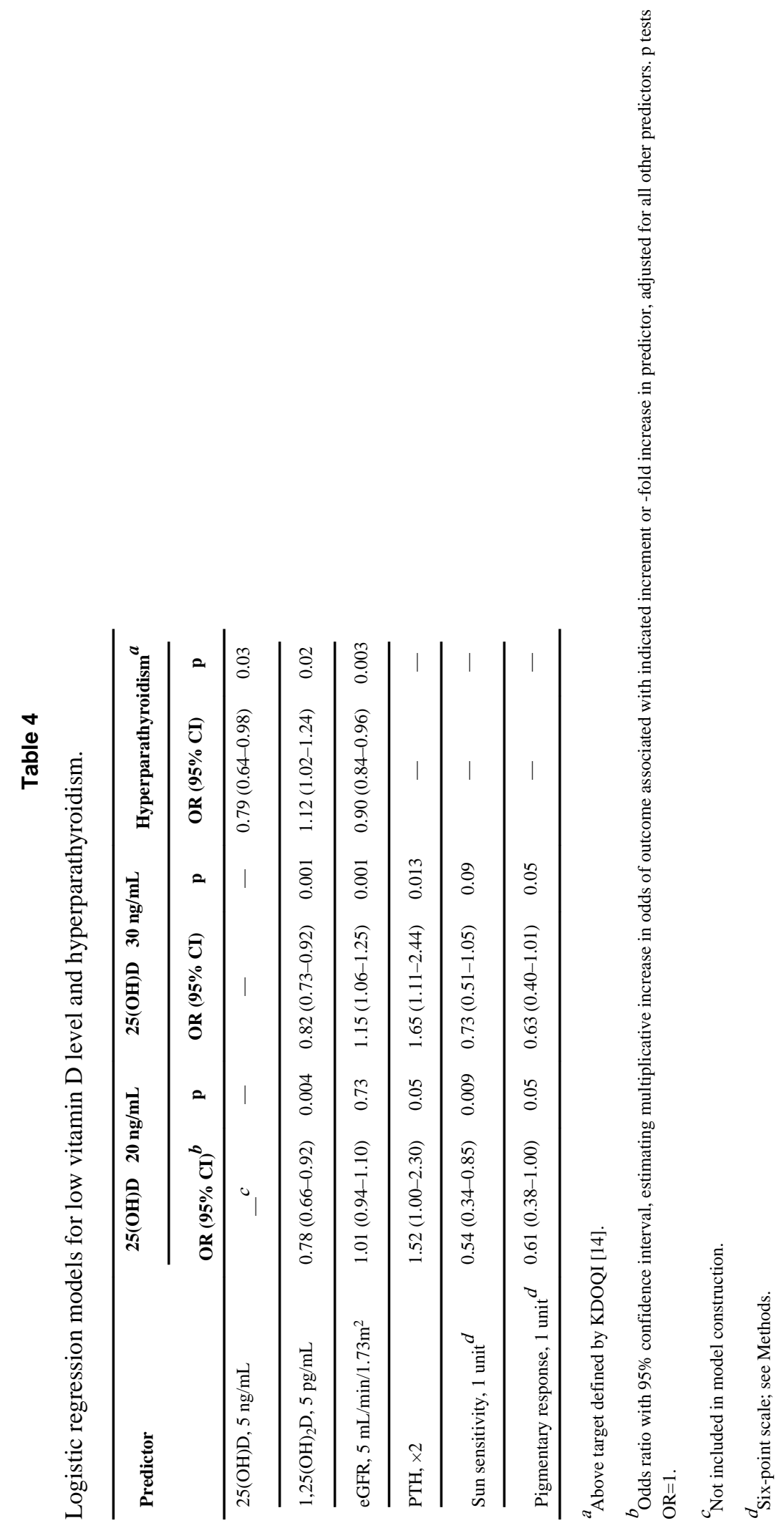

